\title{
1D and 2D site amplification effects at Tarcento (Friuli, NE Italy), 30 years later
}

\author{
Carlo Cauzzi · Ezio Faccioli • Giovanni Costa
}

Received: 31 January 2010 / Accepted: 29 July 2010 / Published online: 2 September 2010

(C) Springer Science+Business Media B.V. 2010

\begin{abstract}
A temporary accelerometer network has been installed in Tarcento (Friuli, NE Italy), a small town heavily hit by the 1976-1977 Friuli earthquake sequence, as a part of an ongoing research project aimed at ground motion simulation and generation of shakemaps in the near-field of an earthquake. The network operated from October 2008 to April 2010 and consisted of three K2 accelerographs with internal Episensor, distributed over a linear array of about $1.5 \mathrm{~km}$ length. Tarcento town had been chosen, at the end of the 1970 s, as the ideal site for a pilot microzonation
\end{abstract}

Electronic supplementary material The online version of this article (doi:10.1007/s10950-010-9202-y) contains supplementary material, which is available to authorized users.

\section{Cauzzi $(\bowtie)$}

Swiss Seismological Service, ETH Zürich,

Sonneggstrasse, 5, 8092 Zürich, Switzerland

e-mail: carlo.cauzzi@sed.ethz.ch

E. Faccioli

Department of Structural Engineering,

Politecnico di Milano,

Piazza Leonardo da Vinci, 32,

20133 Milan, Italy

e-mail: faccioli@stru.polimi.it

G. Costa

Department of Earth Sciences, Università di Trieste,

Via E. Weiss, 1, 34127 Trieste, Italy

e-mail: costa@units.it study, the first of this kind in Italy, in which a substantial number of field (and laboratory) tests were carried out in order to assess the mechanical properties of local alluvium deposits and their complex (3D) geometrical configuration. The data from the temporary network, illustrated herein, allow for proper verification and review of some of the quantitative predictions formulated in the 1980 study. As argued in the discussion section, we also believe that the data are apt to provide valuable information of more general interest on the complex seismic response of alluvium-filled valleys, and we show therein how the observations can be interpreted in the light of presently available parametric simulation studies and simplified criteria for handling basin amplification effects.

Keywords Seismic networks • Microzonation • Alluvium-filled valleys • Complex site effects

\section{Introduction}

This study originates from an Italian governmentfunded research project denominated "Prediction of ground motion and generation of shaking maps in the near-fault region of an earthquake", sponsored within the so-called PRIN2007 national program. The project began in September 2008, with the challenging aim of improving, for earthquake engineering applications, the prediction of 
strong earthquake ground motions in the near field of seismic sources highly representative of earthquake hazard in Italy, especially in its Northeastern regions.

The scarcity of available near-source acceleration records, even worldwide, naturally led the proposers to formulate the numerical simulation of strong ground motions at selected test sites as one of the main tasks of the Project. These sites were chosen at the beginning on the basis of three main criteria, i.e., (a) general nearfault location, (b) well-characterized geological configuration, and (c) potentially interesting or peculiar local seismic response features. Two sites were selected: Gemona del Friuli and Tarcento, in the Friuli Venezia Giulia region of NE Italy.
Both are small towns partially destroyed or heavily damaged by the 1976-1977 Friuli earthquake sequence, with a $M_{W} 6.4$ mainshock occurring on May 6, 1976.

Criterion (a) is apparent in Fig. 1, where the surface projections of the faults that caused the largest earthquakes of the Friuli 1976-1977 seismic sequence are depicted. Reconstructing the geometry of the faults rupturing in the sequence is still a debated issue, beyond the scope of this paper. Herein, we just show the selection of possible source representations adopted within the mentioned research project. The reader is referred to Aoudia et al. (2000), Basili et al. (2008), Burrato et al. (2008), Cipar (1981), DISS Working Group (2009), Galadini et al. (2005), Slejko et al. (1999),

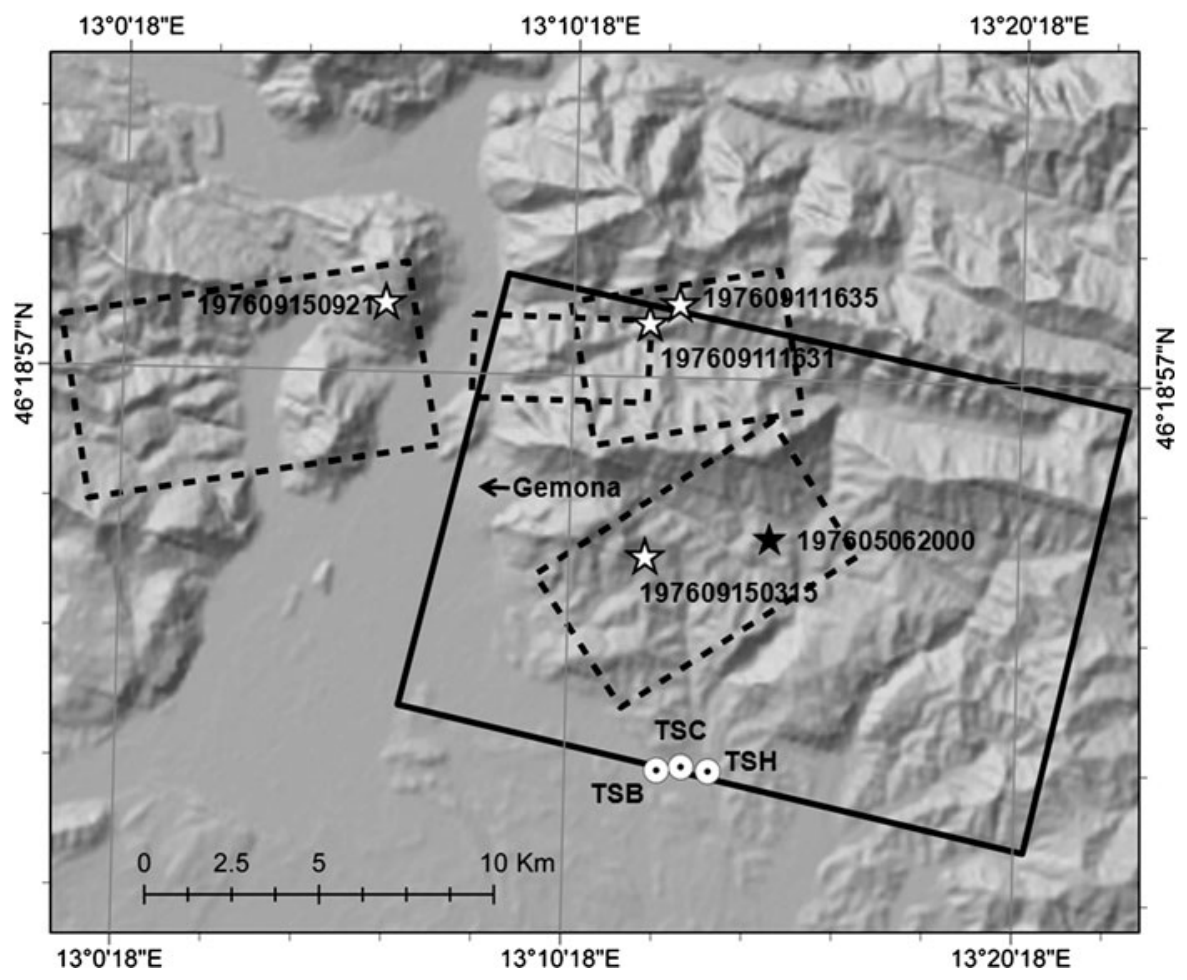

Fig. 1 Surface projections of the faults generating the largest earthquakes of the Friuli 1976-1977 seismic sequence. The solid rectangle represents the surface projection of the 1976 May 6 (20:00 UTC, $M_{W}$ 6.4) earthquake source (Perniola et al. 2004). The related epicenter (Zonno and Kind 1984) is the black star. Dashed rectangles (faults) and white stars (epicenters) refer to the most energetic September 1976 events: Sept. 11 (16:31 UTC, $M_{W}$ 5.2),
Sept. 11 (16:35 UTC, $M_{W}$ 5.7, Sept. 15 (03.15 UTC, $M_{W}$ 6), and Sept. 15 (09:21 UTC, $M_{W}$ 6.1). Fault geometry and epicenter locations are taken from Pondrelli et al. (2001). The circle symbols on the southern border of the 1976/05/06 fault are the accelerometer stations (TSH, TSC, and TSB) installed in the Tarcento municipal area, discussed in text. The black arrow indicates the town of Gemona del Friuli, lying upon a large alluvium fan 
and Zollo et al. (1997) for alternative fault models. Note that both Gemona and Tarcento lie within the surface projection of the fault related to the $M_{W} 6.4$ mainshock.

Tarcento (nowadays a community of about 9,000 inhabitants) had been chosen in the late 1970 s as the ideal candidate for a pioneering, detailed microzonation study, the first of its kind in Italy. The study was jointly carried out by researchers from the University of Trieste and the Technical University (Politecnico) of Milan, on behalf of the Regional Administration of Friuli Venezia Giulia (Brambati and Faccioli 1980).

A distinctive feature of the microzonation study was the substantial number of field and laboratory tests (including nine mechanical continuous borings, with SPT and undisturbed sampling, three $\mathrm{CH}$ pairs, 110 light seismic bases, and

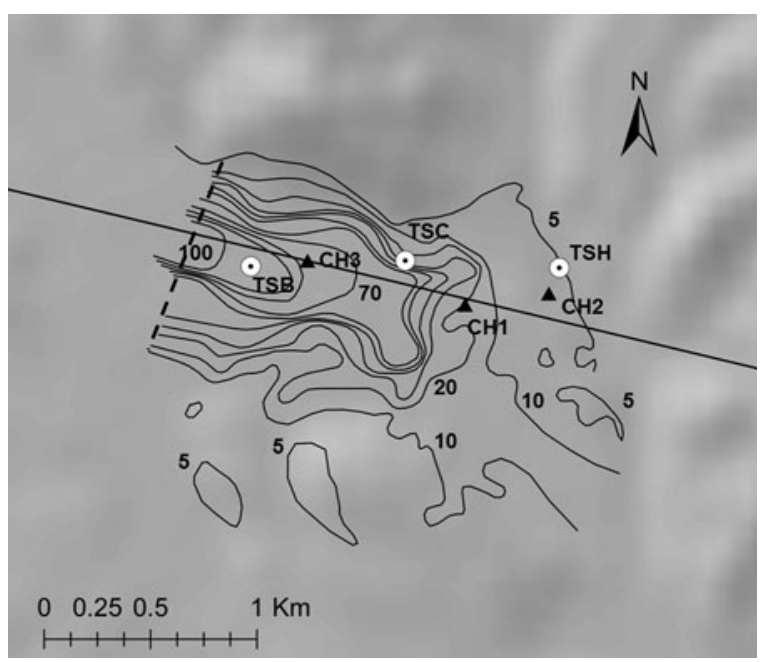

Fig. 2 Digital elevation model in the zone of Tarcento town. Black curves are the depth contours (in meters) of the top of bedrock within the municipal area, as given in Brambati and Faccioli (1980). White symbols show sites of digital accelerometer stations of the temporary seismic network, installed at locations with substantially different thickness of the underlying alluvium sediments. Reference station is the Sports Hall site (TSH), lying on very shallow depth to bedrock. Black triangles denote the crosshole $(C H)$ test sites of the 1980 microzonation study. To facilitate comparison with Fig. 1, the southwestern border of the surface projection of the 1976/05/06 earthquake source is also shown (straight solid line). Also shown is the cross-section of the valley model shown in Fig. 14 (straight dashed line)
$58 \mathrm{VES}$ ) performed for the purpose of defining the geotechnical and geophysical characteristics of the alluvium sediments underlying most of Tarcento town, as well as the geometry of the underlying top of bedrock, consisting of flysch. Field investigations revealed a complex 3D bedrocksediments interface (Fig. 2). Bedrock itself outcrops in the northern and north-eastern parts of town and reaches a maximum depth of about $100 \mathrm{~m}$ in the north-western portion of the municipal area. The geometry of the top of bedrock as reconstructed in Brambati and Faccioli (cit.) discloses a WNW-ESE oriented gully that deepens progressively and is broken by slope discontinuities westwards. This buried gully is assumed to be a former bed of the Torre creek, now flowing southwards in the easternmost part of the municipal area.

\section{Salient findings from the 1980 investigations}

Crucial importance is attributed herein to the shear wave velocity $\left(V_{S}\right)$ profiles measured through three cross-hole $(\mathrm{CH})$ surveys in the old microzonation study (Brambati and Faccioli, cit.), shown in Fig. 3. The $V_{S}$ profile at $\mathrm{CH} 2$, very close to the present Sports Hall site (TSH), is depicted by the dashed curve in Fig. 3. The mechanical boring at this site disclosed the presence of unfractured, marly flysch bedrock $4 \mathrm{~m}$ below the surface, with $V_{S}$ values between 800 and $900 \mathrm{~ms}^{-1}$. The overlying soil is mainly composed of clay and silt with $V_{S}<400 \mathrm{~ms}^{-1}$. Thus, a Eurocode 8 (CEN 2004) ground category A would likely be assigned to the TSH station site, $V_{S, 30}$ being presumably $\geq 800 \mathrm{~ms}^{-1}$.

The $V_{S}$ profile at $\mathrm{CH} 1$ site, located about $250 \mathrm{~m}$ ESE of the present main Public School of Tarcento (TSC), is the solid curve in Fig. 3. In the mechanical boring executed at this site, fractured marly flysch was encountered about $20 \mathrm{~m}$ below ground surface, with $V_{S}$ values of $600-700 \mathrm{~ms}^{-1}$. Alluvium consists here mainly of sandy gravel (with some thin clay layers at depth), and exhibits a $V_{S}$ trend rapidly increasing with depth, up to about $600 \mathrm{~ms}^{-1}$. A Eurocode 8 ground category $\mathrm{B}$ is likely appropriate for $\mathrm{CH} 1$ site, i.e., stiff soil with $360 \mathrm{~ms}^{-1}<V_{S, 30} \leq 800 \mathrm{~ms}^{-1}$. 


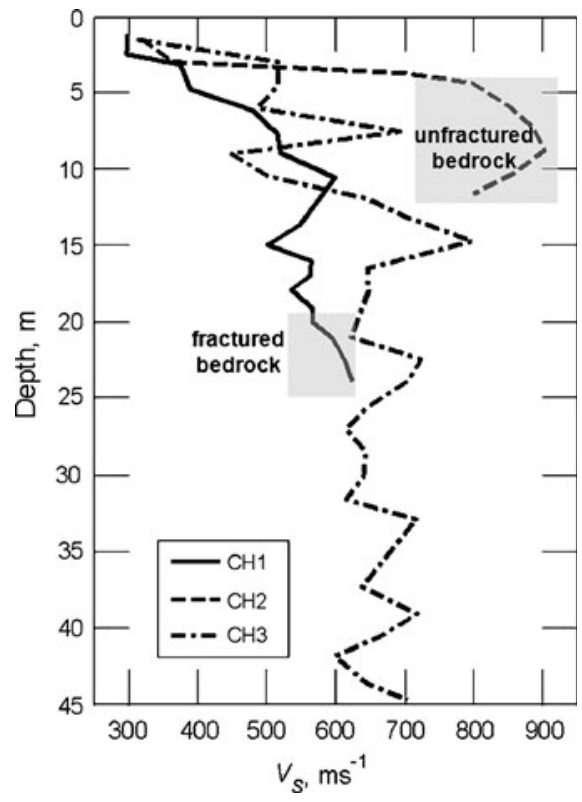

Fig. $3 V_{S}$ profiles measured through three cross-hole $(\mathrm{CH})$ surveys in the old microzonation study (Brambati and Faccioli 1980). At $\mathrm{CH} 2$ site, near the present Sports Hall of Tarcento, the mechanical boring found unfractured, marly flysch bedrock $4 \mathrm{~m}$ below ground surface. $\mathrm{CH} 1$ site lies some $250 \mathrm{~m}$ ESE of the present main Public School of Tarcento. The mechanical boring found fractured marly flysch bedrock about $20 \mathrm{~m}$ below the surface, with overlying soil mainly composed of dense sandy gravel. The $\mathrm{CH} 3$ profile, some $200 \mathrm{~m}$ E of S. Biagio church, is entirely within alluvium material. Here, the mechanical boring encountered fractured marly flysch bedrock $80 \mathrm{~m}$ below ground surface, though the $V_{S} \log$ stops at $45 \mathrm{~m}$ depth

A similar $V_{S}$ profile was detected at site $\mathrm{CH} 3$ (church of San Biagio (TSB), dot-dashed line in Fig. 3). Although the $V_{S} \log$ at $\mathrm{CH} 3$ is limited to $45 \mathrm{~m}$ depth, the mechanical boring was extended here to a larger depth, and fractured marly flysch bedrock was found $80 \mathrm{~m}$ below ground surface. The overlying alluvium consists of sandy gravel, with $V_{S}$ rapidly increasing with depth and reaching a constant mean level of roughly $650 \mathrm{~ms}^{-1}$. Like CH1, a Eurocode 8 (CEN, cit.) ground category $\mathrm{B}$ would be appropriate at $\mathrm{CH} 3$.

The main outcome of the 1980 study was a microzonation map for Tarcento, where different seismic zones were identified within the municipal area. In each zone, amplification factors were provided with respect to the seismic action both at short periods and intermediate periods (around 1 s) stipulated by the 1980 Italian seismic code, ranging from 1.0 to 1.6 (in the border portions of the alluvium basin).

Those amplification factors had been derived, through smoothing, from detailed 2D FEM ground motion response analyses that used as excitation also one record of the September 15 (09:21 UTC) $M_{W} 6.1$ strong aftershock, see Fig. 1, obtained at the historical Tarcento accelerograph station, illustrated in the next section. In the zone of the deepest sediments (close to where station TSB is now located, also described in the next section), the numerical analyses indicated a mean amplification factor with respect to exposed rock conditions close to 1 for response spectrum ordinates at short period and about 3.5 at intermediate periods. Likewise, in a zone of lesser sediment thickness, such as at the location of TSC station (see next section), the same 2D analyses had shown spectrum amplification factors of about 1.4 at short period and as high as 4 at intermediate periods.

Final recommendations were also given in the 1980 study, focused on a program of further investigation including monitoring of earthquakeinduced ground motions through "a small accelerograph network in the Tarcento valley, capable of recording also events of moderate intensity". The main role envisaged for such network was a proper verification of the quantitative ground motion predictions illustrated in the study, and to cast further light on the peculiar earthquake response of alluvium-filled valleys. Thirty years have elapsed since then; the PRIN2007 research project is providing today the opportunity to implement that recommendation. It is the main purpose of this article to illustrate how the goal is being achieved.

\section{Instrumental earthquake observations at Tarcento}

Three accelerometer stations were installed in October 2008 and removed in April 2010. The recording instruments were Kinemetrics K2 accelerographs with internal tri-axial Episensor, operating with the following parameters: (1) trigger 
of the STA/LTA type with STA/LTA $\geq 4$ at least for two channels; (2) pre-event length $=20 \mathrm{~s}$; (3) post-event length $=40 \mathrm{~s}$; (4) acausal trigger filter with $T_{C}=2 \mathrm{~s}$. Each station is equipped with proper AC connection, backup battery, and a 2 Gb PCMCIA card for earthquake data storage. Data were manually downloaded every 3 months (or following relevant earthquakes) during maintenance visits at the sites. As mentioned in the previous section, the installation sites are the municipal Sports Hall, the main public School, and the church of San Biagio, aligned along the EW axis of the Tarcento basin, and forming a linear array of about $1.5 \mathrm{~km}$ length (Fig. 2). The sites were chosen so as to monitor the seismic response of the Tarcento alluvium basin at points with different bedrock depth. Based on Brambati and Faccioli (1980), the alluvium cover was expected to be only about $4 \mathrm{~m}$ thick at TSH (see Fig. 3), while it should reach $30-40 \mathrm{~m}$ at TSC and 90$100 \mathrm{~m}$ at TSB. TSH actually lies very close to the historical Tarcento SM accelerograph station, installed on May 8, 1976, which recorded six strong earthquakes of the 1976 seismic sequence, including the $M_{L} 6$ shock of September 15, 1976,
09:21:18 UTC and was removed in early 1977 (see the Italian Accelerometric database at http://itaca.mi.ingv.it for further details). Figure 4 displays a map of the seismic events recorded by the temporary network. Location of recorded earthquakes as well as estimation of their seismological parameters has been routinely made available by the Seismology and Monitoring Research Group of the Department of Earth Sciences at University of Trieste. Their seismic bulletin (available at http://rtweb.units.it/REAL_ TIME/bulletin.html) lists latitude, longitude, $M_{L}$, and, in most cases, $M_{W}$ determinations of the local and regional earthquakes detected by the Friuli Venezia Giulia permanent accelerometer network, denominated RAF (Costa et al. 2009). This was the first digital seismic network installed in Italy (1993-1995).

Although, for graphical reasons, the map of Fig. 4 only shows earthquakes located within $50 \mathrm{~km}$ distance from TSH, the Tarcento network clearly recorded important regional events, including the Parma-Frignano 2008 mainshock $\left(23 / 12 / 2008,15: 24: 21, M_{L}\right.$ 5.1, $M_{W}$ 5.4) and the L'Aquila 2009 mainshock (06/04/2009, 01:32:39
Fig. 4 Epicenters (white circles) of events recorded by the Tarcento accelerometer network. The symbol size is proportional to local magnitude, ranging from 0.7 to 3.6 . Only earthquakes located within $50 \mathrm{~km}$ distance from TSH station (black triangle) are shown on the map; 142 earthquakes were clearly detected by the Tarcento array between October 2008 and April 2010




Fig. 5 NS ground accelerations, unfiltered, recorded at Tarcento in the $M_{W} 6.3$ L'Aquila mainshock, $R_{E} \approx 432 \mathrm{~km}$. Bottom panel displays for comparison the NS acceleration waveform recorded at the permanent VINO station less than $10 \mathrm{~km}$ distance from Tarcento

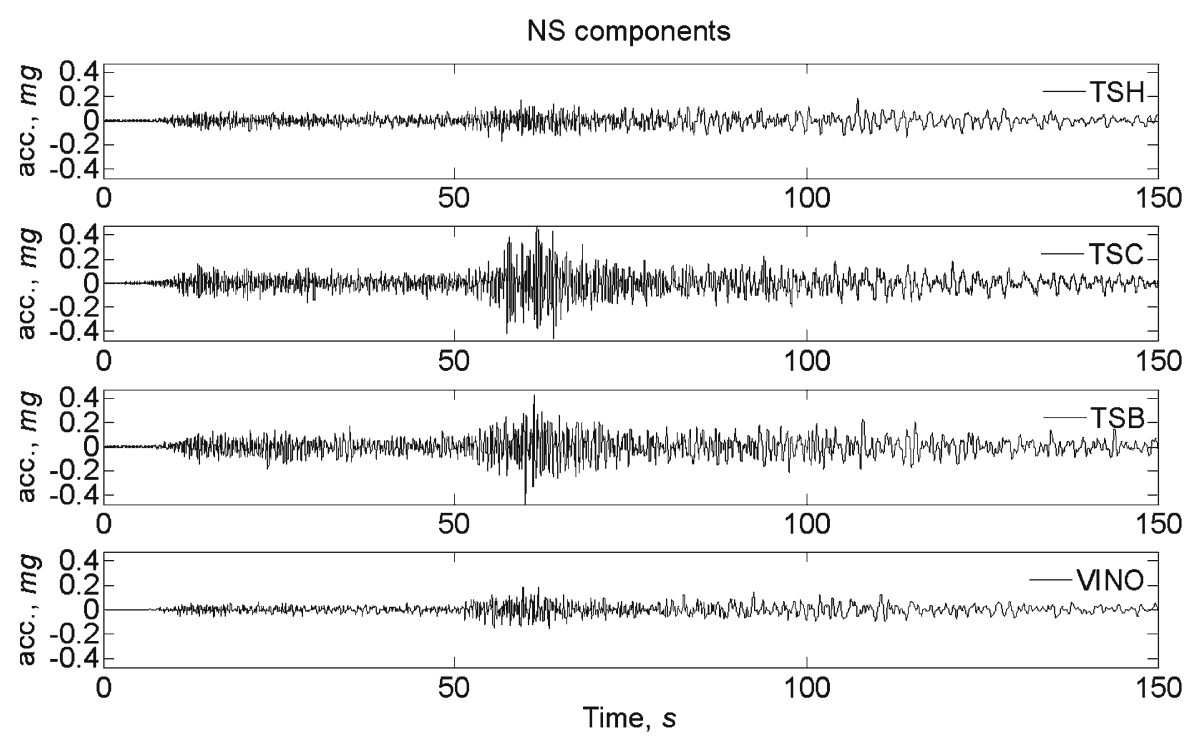

UTC, $M_{L}$ 5.8, $M_{W}$ 6.3) with its strongest aftershocks. The $M_{L}$ values of local events recorded by the temporary network did not exceed 3.6.

The unfiltered NS acceleration components of the L'Aquila mainshock recorded at Tarcento, at epicentral distance $R_{E} \approx 432 \mathrm{~km}$, are illustrated in Fig. 5, where the waveform recorded at the RAF permanent seismic station of Villanova delle Grotte (VINO, less than $10 \mathrm{~km}$ distance from Tarcento) is also shown for comparison. The VINO station is installed within a natural rock cave. The peak acceleration values $(P G A)$ at TSH do not exceed $0.2 \mathrm{mg}$, comparable to those recorded at VINO. Though definitely insignificant for engineering purposes, the $P G A$ values may cast some light on the extent of site effects that can be expected on the Tarcento alluvium-filled basin. Actually, $P G A$ reaches $0.5 \mathrm{mg}$ at TSC and TSB.

On the other hand, in the record of a $M_{W} 2.6$ local earthquake at epicentral distance $\approx 9 \mathrm{~km}$, shown in Fig. 6, PGA at TSH is comparable to
Fig. 6 NS ground accelerations, unfiltered, recorded at Tarcento in an $M_{W} 2.6$ local earthquake, $R_{E}=9 \mathrm{~km}$
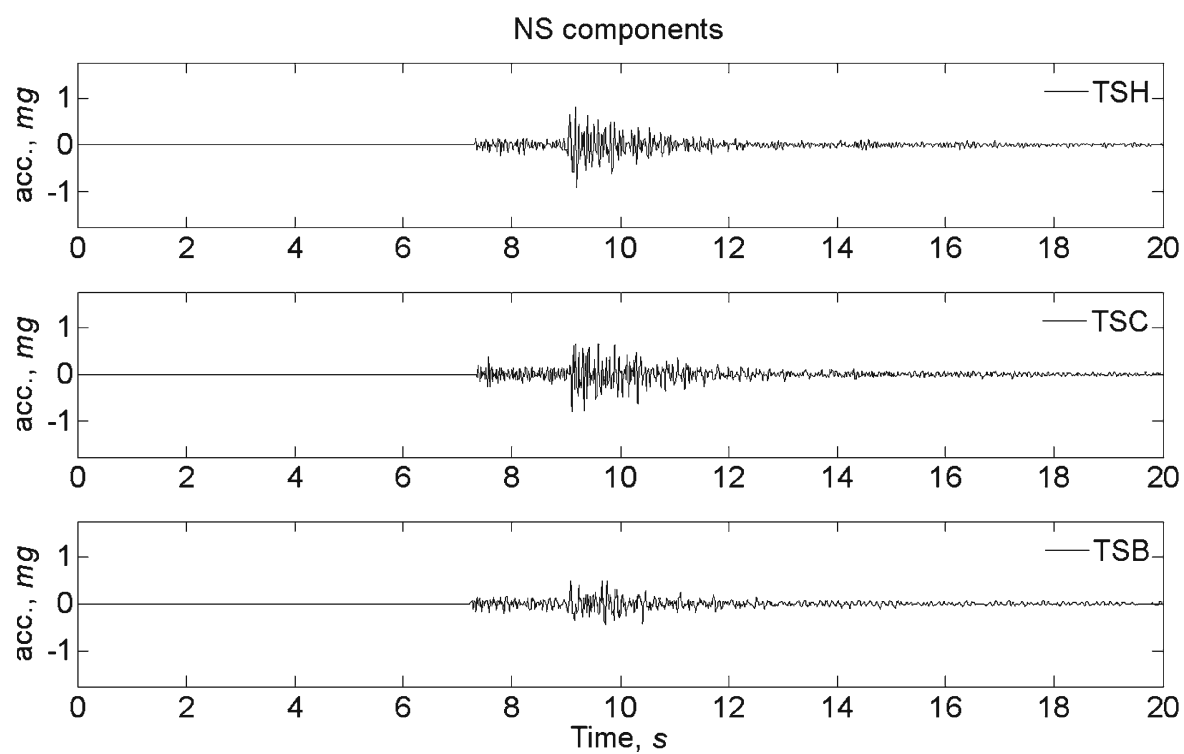
that observed at TSC, while deamplification of seismic waves can be appreciated at TSB. Furthermore, even a quick visual inspection of the waveforms shows that the signal at TSB is significantly poorer in high frequencies. The EW components of ground motions, not shown here, exhibit a similar behavior. These simple findings provide just a hint at the remarkable differences in seismic response that may be expected across the small Tarcento basin, depending on the frequency content of incoming waves, as it will be made more evident in the following section. A list of the earthquakes well recorded by the temporary network, with the associated $P G A$ values for all channels, can be found in Online Resource 1.

\section{Data analysis: HVSRs and SSRs}

In this section, we experimentally analyze the main characteristics of earthquake site response at Tarcento through spectral analyses of the best earthquake recordings obtained with the temporary accelerometer array. We applied the noreference-site $\mathrm{H} / \mathrm{V}$ spectral ratio (hereinafter HVSR) technique, as well as the reference-site standard spectral ratio method (SSR, Borcherdt 1970), to a significant subset of the records described in the previous section. Among the empirical methods for site response analyses, the HVSR technique applied to ambient noise, also known as the "Nakamura technique"(Nakamura 1989), has been widely used since it was first introduced by Nogoshi and Igarashi (1971) based on the pioneering studies of Kanai and Tanaka (1961). The theoretical background of the method, as well as the procedures for field experiments were also extensively investigated, see e.g., Nakamura (2000), Bard (2008), Chatelain et al. (2008), Guillier et al. (2008), and Haghshenas et al. (2008). Nevertheless, the assessment of site amplification relying only on microtremor measurements may lead to unreliable results, as demonstrated in many studies (Lermo and Chàvez-Garcìa 1993; Lachet and Bard 1994; Bindi et al. 2000; Parolai et al. 2004 amongst others). This makes the recording of suitable datasets of seismic events strongly advisable if a more accurate site response evaluation is to be obtained.

To ensure satisfactory signal-to-noise ratio values, only records of events with $M_{L} \geq 2$ were retained for the analyses. The average signal-tonoise ratios (SNR) for the selected earthquake recordings at the accelerometric stations are shown in Fig. 7. "Noise" spectra were computed on the basis of the pre-event window of each recording, while "Signal" spectra were obtained using $30 \mathrm{~s}$ length accelerometric traces. As apparent from Fig. 7, the average SNR are always larger than 3 for frequencies $f>0.5 \mathrm{~Hz}$. Only for the EW components of ground motions at TSC and TSB, the average SNR values are slightly lower than 3 for frequencies $f<0.5 \mathrm{~Hz}$. Furthermore,
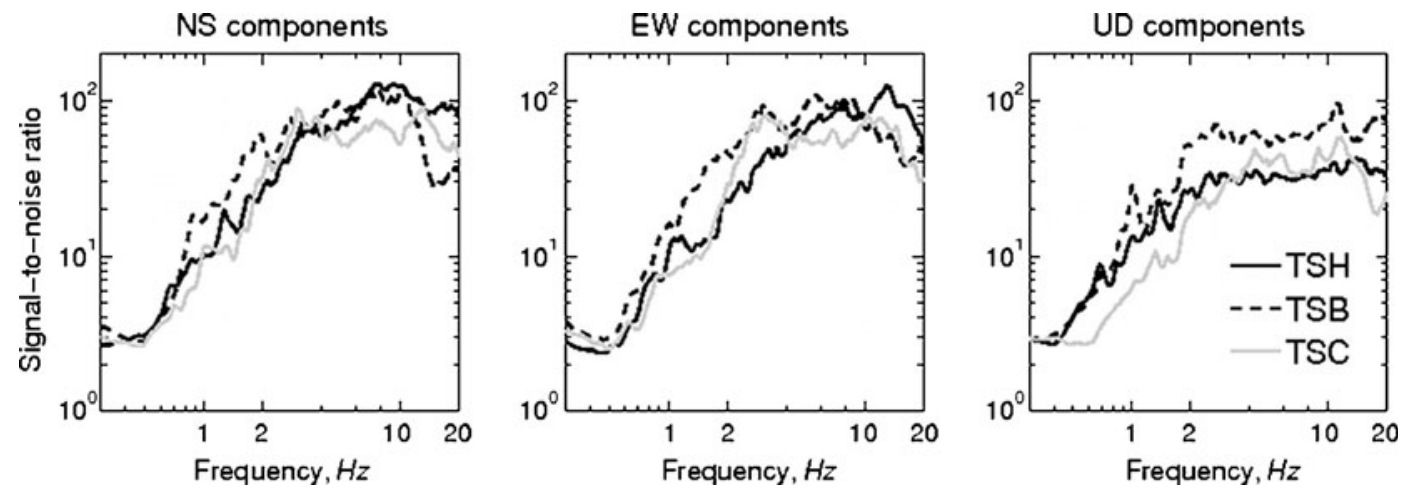

Fig. 7 Average signal-to-noise ratios as obtained from the earthquake records used for HVSR and SSR computations at the installation sites TSH, TSB, and TSC, as described in the text 
waveforms contaminated by spikes or transient apparent disturbances were discarded. The earthquakes considered for analysis were those identified with an asterisk in Online Resource 1.

Fourier spectra of local earthquakes were computed on $30 \mathrm{~s}$ long time windows and no significant impact was observed in the results when neglecting the P-wave phases of ground motions. For regional earthquakes (Parma 2008 and L'Aquila 2009), Fourier spectra were computed based on time windows covering the S-wave phase of the recordings. Spectra were smoothed through a function of the Konno and Ohmachi (1998) type, having constant bandwidth on a log scale and therefore generally recommended for regularizing low frequency amplitudes of Fourier spectra. The Konno and Ohmachi (cit.) smoothing function is typically used in HVSR computations with bandwidth $b=40$ and the same value has been adopted in the present study. Analyses were performed by means of the combined Fourier spectra of the EW and NS channels of ground motions (through geometric mean), after finding no significant differences in the results when taking separately the horizontal channels or segregating the earthquakes according to the relative azimuth with respect to Tarcento valley.

At each installation site, recordings of the ambient noise levels were also acquired. Lennartz $3 \mathrm{D}-5 \mathrm{~s}$ velocity sensors were used for the noise measurements, which lasted at least $30 \mathrm{~min}$ at each site. Noise recordings and data analyses were carried out consistently with the guidelines for the implementation of the $\mathrm{H} / \mathrm{V}$ spectral ratio technique on ambient vibrations, as prepared within the framework of the European SESAME (Site EffectS assessment using AMbient Excitations) project, and subsequently published (Bard 2008). Note however that all noise measurements were performed during the day and therefore, the possible presence of monochromatic noise sources, produced, e.g., by machineries at work or other cultural activities, could not be avoided.

Figure 8a displays the HVSR at TSH station. The shaded band encompasses the median $\pm 1 \sigma$ levels as obtained from the selected local and regional events. The HVSR curves obtained from earthquake recordings are nearly flat up to about $4 \mathrm{~Hz}$, while significant amplification is apparent over a broad frequency range between 4 and $15 \mathrm{~Hz}$, with peak values around $8 \mathrm{~Hz}$. Amplification in the ambient noise-based HVSR curve in the range $0.3-1 \mathrm{~Hz}$ does not display a clear peak and cannot be explained on the basis of site geology. The sharp peak apparent on the same curve around $1.7 \mathrm{~Hz}$ is most likely due to a monochromatic source of industrial origin. Note that the HVSR of ambient noise at this station hardly reaches the lower bound of the HVSR amplitudes of earthquakes for frequencies $f>$ $2 \mathrm{~Hz}$. In Fig. 8b the strong motion HVSR curves at

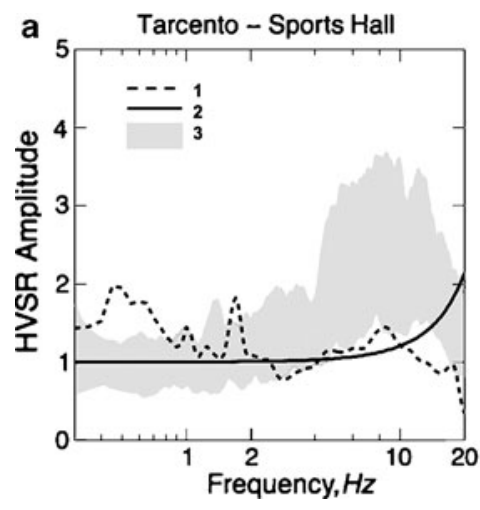

Fig. 8 a HVSR from weak motion records at Sports Hall site, TSH. 1 is the average HVSR curve obtained from ambient noise recordings, 2 is the simulated $1 \mathrm{D}$ amplification function at the site, as described in the text, and shaded

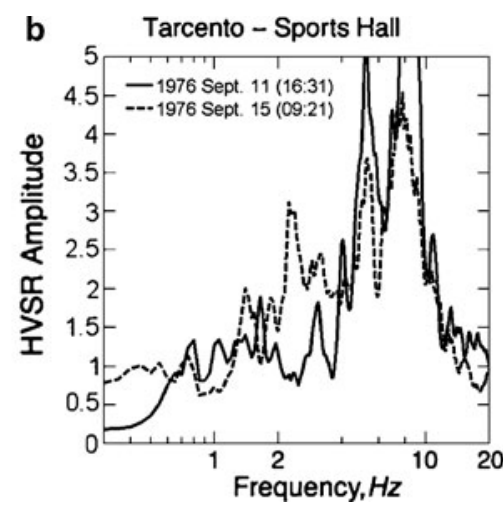

band 3 depicts the median \pm 1 SE amplification from selected local and regional events. b HVSR curves obtained from the best strong motion records of 1976 events at the historical Tarcento SM station 
the historical Tarcento accelerograph station are shown. The curves were obtained through spectral analysis of the best recordings available, i.e., the 1976 Sept. 11 (16:31 UTC, $M_{W}$ 5.2) and Sept. 15 (09:21 UTC, $M_{W}$ 6.1) waveforms: note the remarkable consistency between these curves and those obtained from the weak motion recordings at TSH (Fig. 8a).

Figure $9 \mathrm{a}$ and $\mathrm{b}$ display the elastic 5\% damped horizontal response spectra (solid curves) as computed from the available records (see itaca.mi. ingv.it) of the largest aftershock recorded at Tarcento during the Friuli sequence, i.e., the $M_{W} 6.1$ event occurred on 1976 Sept. 15 (09:21). Consistently with the representation of earthquake sources adopted within the PRIN2007 research project (see Fig. 1), the focal distance of Tarcento station, though unfortunately affected by large uncertainties, is assumed equal to $19 \mathrm{~km}$. Use has been made here of corrected (processed) waveforms, band-pass filtered between 0.15 and $15 \mathrm{~Hz}$ (see Paolucci et al. 2010). Subsequently, the response spectra of the two as recorded orthogonal horizontal components have been combined through their geometric mean. The observed spectra are compared in Fig. 9 with the response spectrum values predicted by a recent ground motion prediction equation (Cauzzi and Faccioli 2008), mainly based on Japanese digital high-quality ac- celerometer data not including the record under examination. The dashed curves in Fig. 9 represent the median predictions of the ground motion prediction equations (GMPEs), while the lower and upper bound of the shaded bands represent the 16- and 84-percentile of the distribution of the predicted spectral values, respectively. The observed displacement response spectrum (Fig. 9a) is well predicted by the Cauzzi and Faccioli GMPEs for periods $T \leq 1 \mathrm{~s}$, while at larger periods it approaches the 16-percentile level of the predictions. On the other hand, the median pseudo-acceleration spectrum derived from the previous GMPEs agrees quite well with the observed one, although the effect of the thin surface soil layer covering rock at TSH is strongly apparent and results into a spectral peak at about 0.15-0.2 s, more appropriate for a Eurocode 8 (CEN 2004) ground category B rather than A.

HVSR at TSC are shown in Fig. 10a. The curves obtained through analysis of earthquake data and ambient noise show two broad amplification bands, the first between 2 and $4 \mathrm{~Hz}$ and the second between 6 and $15 \mathrm{~Hz}$. Also in this case, there is a general lack of consistency between noise and earthquake based results for $f<1 \mathrm{~Hz}$, while the sharp peak apparent on the noise-based HVRS curve has most likely an industrial origin. SSR amplitude values (Fig. 10b) with respect to TSH

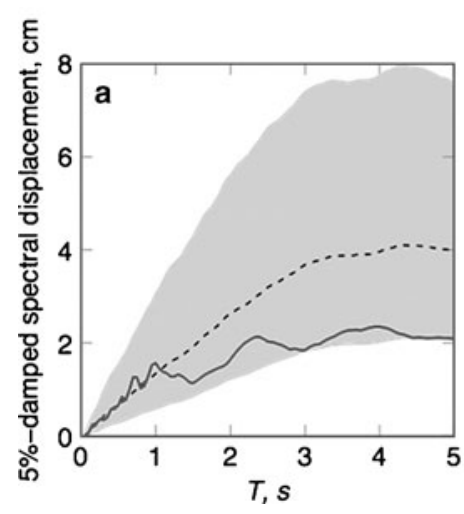

Fig. 9 Elastic 5\% damped spectral displacements (a) and pseudo-accelerations (b) at Tarcento for the Sept. 15, 1976 (09:21) $M_{W} 6.1$ Friuli aftershock. Hypocentral distance from TSH is equal to $19 \mathrm{~km}$. Curves 1 represent the median response spectrum prediction by Cauzzi and Faccioli

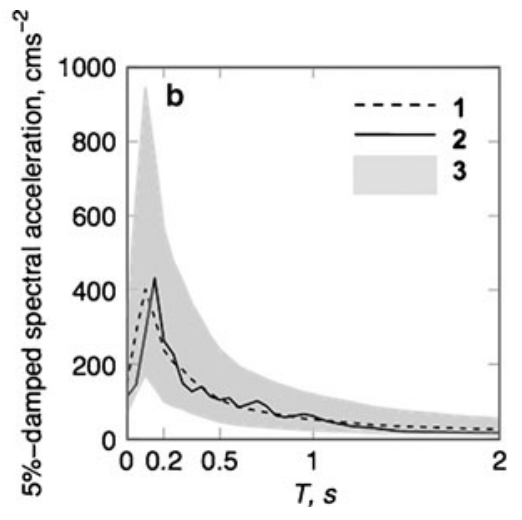

(2008). The shaded bands 3 encompass the 16 and 84 percentile of the distribution of the spectral values predicted by the ground motion attenuation model, while 2 are the observed spectra, as computed from the processed data available for download at itaca.mi.ingv.it 


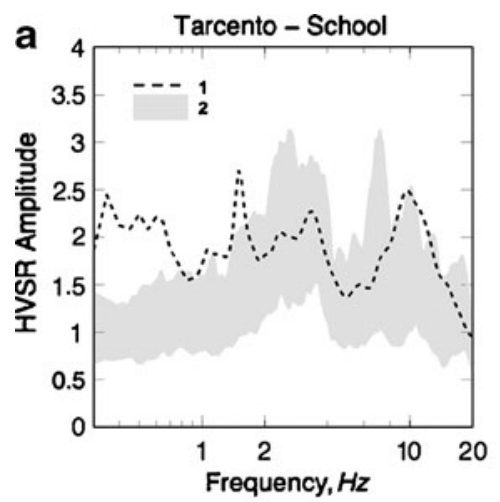

Fig. 10 a HVSR at TSC. 1 is the average HVSR curve obtained from ambient noise recordings, while shaded band 2 depicts the median $\pm 1 \mathrm{SE}$ amplification from selected local and regional events. b 1 simulated 1D site amplification function at the site, shown as a function of frequency normalized w. r. to $f_{0,1 \mathrm{D}}$ (fundamental $1 \mathrm{D}$ frequency of alluvium profile where depth to bedrock is largest $=1.4 \mathrm{~Hz}$ );

clearly identify a significant amplification range between 2 and $4 \mathrm{~Hz}$.

The HVSR amplification curves at TSB are illustrated in Fig. 11a. The curves derived both from earthquake data and from ambient noise show

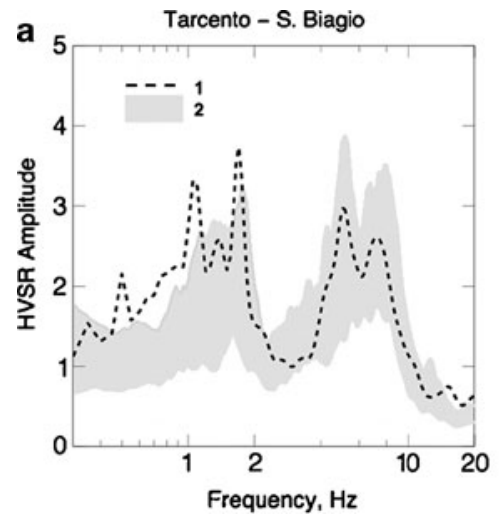

Fig. 11 a HVSR at TSB. 1 is the average HVSR curve obtained from ambient noise, while shaded band 2 depicts the median \pm 1 SE amplification from selected local and regional events. b 1 simulated 1D site amplification function at the site, described in the text, shown as a function of frequency normalized w. r. to $f_{0,1 \mathrm{D}}$ (fundamental 1D frequency of alluvium profile where depth to bedrock

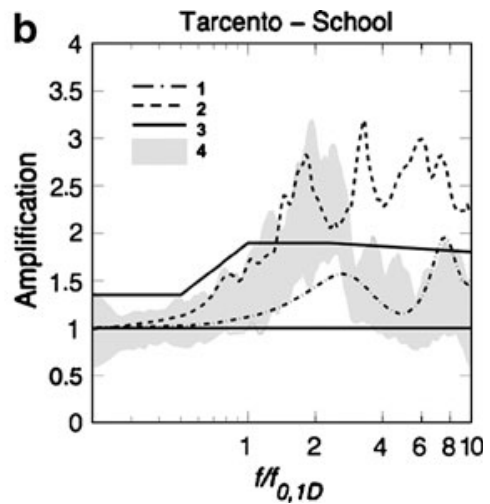

2 2D average Fourier spectral amplification curve in edge zone of Sismovalp model valley (Fig. 12), discussed in text; 3 simplified lower and upper bounds of basin response spectrum amplification on ground type B according to Vanini et al. (2007); 4 SSR median \pm 1 SE amplification at TSC with respect to TSH

two broad amplification bands, the first between 1 and $2 \mathrm{~Hz}$ and the second between 4 and $10 \mathrm{~Hz}$. The consistency between noise-based and earthquake-based results is in this case remarkable for $f>1 \mathrm{~Hz}$. The TSB/TSH spectral ratios,

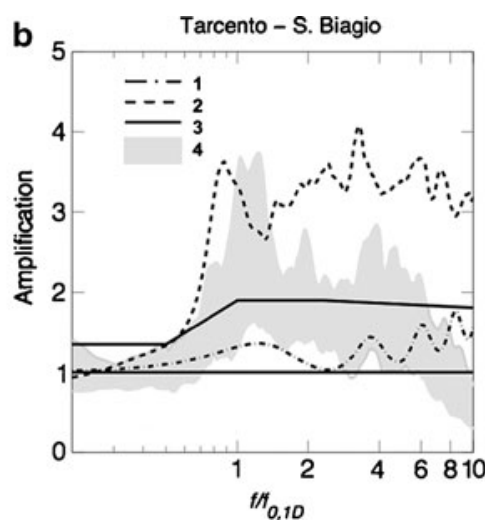

is largest $=1.4 \mathrm{~Hz}$ ); 2 2D average Fourier spectral amplification curve for center zone of Sismovalp model valley (Fig. 12), discussed in text; 3 simplified lower and upper bounds of response spectrum amplification on ground type B in basin center zone according to Vanini et al. (2007); 4 $\mathrm{SSR}$ median $\pm 1 \mathrm{SE}$ amplification at TSB with respect to TSH 
shown on Fig. 11b, emphasize the amplification effects between 1 and $2 \mathrm{~Hz}$ with 84-percentile values reaching almost 4 .

\section{Discussion: 1D vs. basin amplification effects}

The weak earthquakes observations seem to confirm some of the main indications of the old microzonation study (Brambati and Faccioli 1980), in which several 2D dynamic FEM analyses (using recorded accelerograms as excitation) had been carried out to quantify amplification factors for response spectra in different zones of the Tarcento basin. Specifically, that study highlighted the occurrence of typical broadband (2D) site amplification where the alluvium sediments are thickest.

On the other hand, the simulated 1D site amplification curves at the TSH, TSC, and TSB sites, shown in Figs. 8a, 10b, and 11b, do not agree well with the observations. The $1 \mathrm{D}$ curves have been obtained under the assumptions of linear viscoelastic behavior of the alluvium materials, and based on the expected bedrock depth and $V_{S}$ profiles at the recording sites, as indicated in Brambati and Faccioli (cit.). In particular, the $V_{S}$ profile at $\mathrm{CH} 3$ was used for both TSC and TSB, with bedrock depth set at 40 and $95 \mathrm{~m}$, respectively. As apparent from Figs. 10b and 11b, only at TSB the frequency band of significant amplification is well predicted in the simulated 1D transfer functions. The two distinct amplification bands observable in the experimental amplification curves at TSC and more notably in the HVSR envelope at TSB, suggest the presence of two significant velocity gradients at depth. The shallowest one should correspond to the sharp increase in $V_{S}$ in the uppermost 10-15 $\mathrm{m}$ of the sandy gravel deposit, while the second gradient is likely to be represented by the alluvium-bedrock contact at 30-50 m depth at TSC and at 80-90 m depth at TSB. Furthermore, the multi-modal nature of both HVSR and SSR curves is likely to reflect the occurrence of $2 \mathrm{D}$ or $3 \mathrm{D}$ site effects, linked to the complex bedrock configuration. This aspect is discussed in more detail below. We also recall here that no clear evidence was found of differences in the site response in the EW and NS directions, nor of azimuthal dependence of amplification effects.

Herein, we try to interpret observations with tools available from previous studies.

From the experimental viewpoint, several cases have been documented worldwide of strong motion data recorded on alluvium-filled basins, showing amplification levels that largely exceed, at intermediate and long periods, those predicted by empirical ground motion prediction equations or included in seismic codes (see e.g., CEN 2004). Notable among such observations are those from the Umbria-Marche (Italy) seismic sequence of 1997, in which the shaking recorded in the Gubbio Plain basin exhibits very high spectral amplification at periods $2 \mathrm{~s}<T<4 \mathrm{~s}$ (see e.g., Pacor et al. 2007). As is well known, the occurrence of "basin effects" depends on the generation of diffracted waves at the edges of the valley, resulting into surface waves that travel horizontally in the upper basin sediments.

While the seismic response of alluvium-filled valleys and basins in general has been the object of substantial research in the last few decades, only few attempts have been made at providing simplified criteria for practical applications, such as spectral amplification factors linked to a zonation of the valley, rather than to single specific locations (e.g., Chávez-García and Faccioli 2000). Such simplified approaches include studies performed in a previous project denominated "S5Seismic input in terms of expected spectral displacements", executed in 2005-2007 (http:// progettos5.stru.polimi.it/). There, the main aim had been to approximately quantify how response spectra on top of the sediments should be modified to account for basin effects, as shown in a preliminary illustration of that work (Faccioli et al. 2007). The S5 approach (Vanini et al. 2007) relied upon parametric numerical simulations, carried out with a domain reduction method (DRM), a technique that allows to couple the separate analyses of source and basin response. This method, proposed in Bielak et al. (2003) on the basis of earlier work, was subsequently extended 
in a spectral element framework (Faccioli et al. 1997) and implemented in numerical codes suited for $2 \mathrm{D} / 3 \mathrm{D}$ wave propagation analyses (Faccioli et al. 2005).

The main steps of the analyses can be selectively summarized as follows. First a detailed 2D numerical model of the alluvium-filled basin at hand is prepared. Then the source mechanisms of interest are defined and the complete 3D displacement field in the zone occupied by the basin is computed using a horizontally layered local model of the Earth crust, through the efficient analytical method of Hisada and Bielak (2003). The resulting displacement time histories, properly manipulated, are used to calculate the effective forces to be applied at the boundary of the 2D model of the basin as an equivalent, effective dynamic excitation. Wave propagation inside the basin is then performed with the spectral code GeoELSE (Stupazzini et al. 2009, see also geoelse.stru. polimi.it) and the $5 \%$-damped $D R S$ are finally calculated and analyzed at the basin surface receivers. The model valley cross-section used in the present study, shown in Fig. 12, had been borrowed from the European project Sismovalp, so as to be representative of Alpine valleys configurations and mechanical properties of alluvium sediments (Lacave and Lemeille 2006).

The cross-section of the valley is subdivided into five zones (lateral edges and a wider center zone) aimed at capturing differences in the site response features. The analysis included normal, reverse, and strike slip focal mechanisms. The dip angle of the fault was chosen to correspond to typical earthquake sources of the Italian Alpine region. Fault parameters were computed using literature correlations.

To investigate the influence of different types of seismic radiation from the source onto the valley, different basin-fault configurations were chosen for the simulations (see Faccioli et al. 2007). Distances from fault center to valley center of about 15 to $20 \mathrm{~km}$ were used, and magnitudes $M_{W}$ originally of 5.2,6.0, and 6.5. These parameter ranges were recently extended to include $M_{W} 6.3$ and near-field receiver-to-fault distances of 5 to $16 \mathrm{~km}$ (Faccioli et al. 2010).

The 5\%-damped spectra were computed at the surface of the valley from the synthetic accelerograms. For each receiver, ratios with respect to spectrum values on outcropping rock were then computed and averaged within each valley zone and for the different fault mechanisms and valleyfault configurations. In all analyses the fundamental 1D vibration period of the sedimentary column at valley center, $T_{0,1 \mathrm{D}}$, was recognized as a key parameter, acting as a sort of theoretical upper bound for 2D amplification effects (ChávezGarcía and Faccioli 2000). For higher magnitudes, the tendency to enhance longer response periods, always around $T_{0,1 \mathrm{D}}$, was well attested in the simulations.

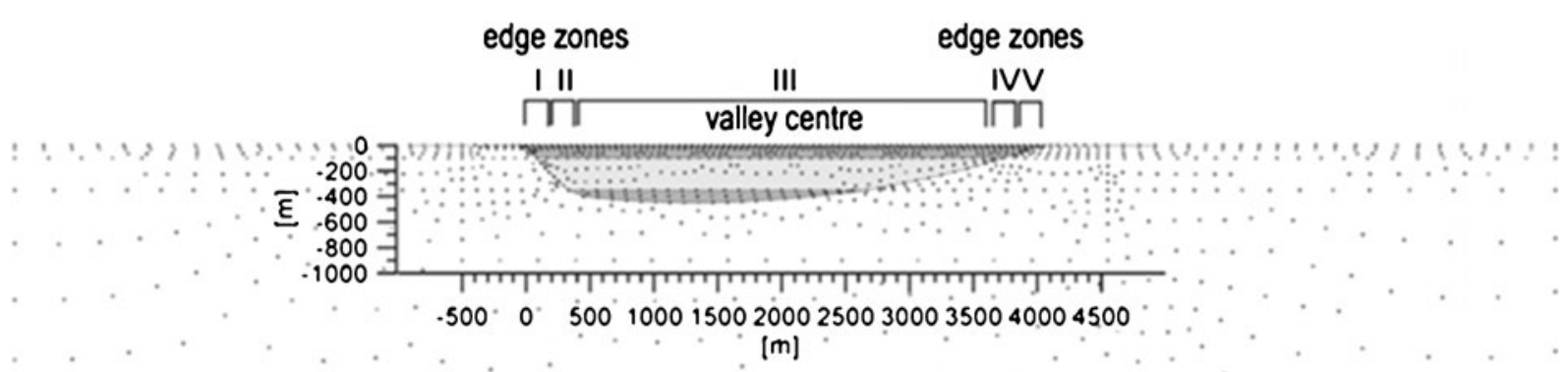

Fig. 12 Valley model adopted by Vanini et al. (2007) with numerical grid (spectral nodes). Note zone subdivision in center zone and edge zones of the valley $(I, I I, I I I, I V, V)$ 
Table 1 Values of $T_{1}, T_{2}$, and $T_{3}$ in Eq. 1 for the different ground categories

\begin{tabular}{llll}
\hline $\begin{array}{l}\text { Ground } \\
\text { category }\end{array}$ & $T_{1}, \mathrm{~s}$ & $T_{2}, \mathrm{~s}$ & $T_{3}, \mathrm{~s}$ \\
\hline $\mathrm{B}$ & 0.3 & 0.7 & 3 \\
$\mathrm{C}, \mathrm{E}$ & 0.3 & 0.7 & 3 \\
$\mathrm{D}$ & 0.3 & $1.2-0.5\left(V_{S, 30}-100\right) /(180-100)$ & 3 \\
\hline
\end{tabular}

The extensive numerical simulations carried out made it possible to formulate practical recommendations, concerning response spectral amplification with respect to rock to be used to account for basin edge effects in design applications.

Basic for such applications is a zonation of the valley in order to discriminate between "central" and "edge" zone behavior (see Fig. 12); analysis of the results showed that edge zones could be defined within a distance of about $x=0.13 L$ from the edges, where $L$ is the valley width. The spectral amplification inside the basin was defined starting from a code-like approximation of the amplification factors $f_{\text {SITE }}\left(T ; V_{S, 30}\right)$ predicted through the Cauzzi and Faccioli (2008) GMPEs, introducing bands with piecewise linear boundaries based on three control periods $T_{1}, T_{2}$, and $T_{3}$, the values of which are given in Table 1 :

$$
\begin{aligned}
& T=0 \mathrm{~s}: \quad f_{\text {SITE }}=f_{0}=1.75 \\
&- 0.75\left(V_{S, 30}-360\right) /(800-360), \\
& \text { ground type B }
\end{aligned}
$$

$$
\begin{aligned}
f_{\text {SITE }}= & f_{0}=1.75-0.5\left(V_{S, 30}-180\right) /(360-180), \\
& \text { ground types C and } \mathrm{E}
\end{aligned}
$$

$$
\begin{aligned}
f_{\text {SITE }}= & f_{0}=1.75-0.5\left(V_{S, 30}-100\right) /(180-100), \\
& \text { ground type D }
\end{aligned}
$$

$$
0 s<T \leq T_{1}: \quad f_{\text {SITE }}=T\left(f_{p}-f_{0}\right) / T_{1}+f_{0}
$$

$$
T_{1}<T \leq T_{2}: \quad f_{\mathrm{SITE}}=f_{p}=\left(800 / V_{S, 30}\right)^{0.8}
$$

$$
\begin{aligned}
T_{2}<T \leq T_{3}: \quad f_{\text {SITE }}= & f_{p}-\left(f_{p}-f_{l p}\right) \\
& \times\left(T-T_{2}\right) /\left(T_{3}-T_{2}\right) \\
T>T_{3}: \quad f_{\text {SITE }}=f_{l p}= & \left(800 / V_{S, 30}\right)^{0.375}
\end{aligned}
$$

Ground types A, B,...are those of Eurocode 8 (CEN 2004). $T_{2}$ is a function of $V_{S, 30}$ for ground category $\mathrm{D}$, which allows for a smooth reduction of maximum amplification at intermediate periods, moving from ground $\mathrm{D}$ to ground $\mathrm{C}$.

$T_{1}$ and $T_{2}$ define the period range of constant amplification, while $T_{2}$ and $T_{3}$ define the range of spectral decay at longer period. The amplitudes of the amplification bands (shaded zones in Fig. 13) are defined from $V_{S, 30}$ maximum and minimum values of Eurocode 8 ground categories.

The practical recommendations obtained through the numerical simulation by Vanini et al. (2007) state that the amplification bands \# 2 of Fig. 13 defined for B, C, and D ground conditions are applicable in the edge zones. On the other hand, for valley center zones, irrespective of specific location, it was proposed that the constant amplification range starting at $T_{1}$ in Eq. 1 should extend to $T_{0,1 \mathrm{D}}$ (for $T_{0,1 \mathrm{D}} \geq T_{2}$ ), and should be followed by a decreasing amplification branch up to a period equal to $2 T_{01 \mathrm{D}}$. In other words, in Eq. $1, T_{2}$ should be replaced by $T_{0,1 \mathrm{D}}$, and $T_{3}$ by $2 T_{0,1 \mathrm{D}}$. On sediments of ground type $\mathrm{B}$ and $M_{W}>6$ events, the use of spectral amplification bands for the class C (or D) soil had been suggested.

Application of the foregoing criteria to the Tarcento basin results in the amplification ranges enclosed within curves \# 3 (solid black lines) in Figs. 10b and 11b. Here, the frequency has been normalized with respect to the 1D fundamental frequency $f_{0,1 \mathrm{D}}=1.4 \mathrm{~Hz}$ which corresponds to the period $T_{0,1 \mathrm{D}}=0.7 \mathrm{~s}$, assumed as representative for the Tarcento valley based on HVSRs and SSRs at TSB. As a check, the main SSR peak in Fig. $11 \mathrm{~b}$ is fairly close to 1 . In the said figures, the lower bound (no amplification) curve 3 corresponds to $V_{S, 30}=800 \mathrm{~ms}^{-1}$, i.e., the threshold between $\mathrm{A}$ and $\mathrm{B}$ ground types, and the upper 

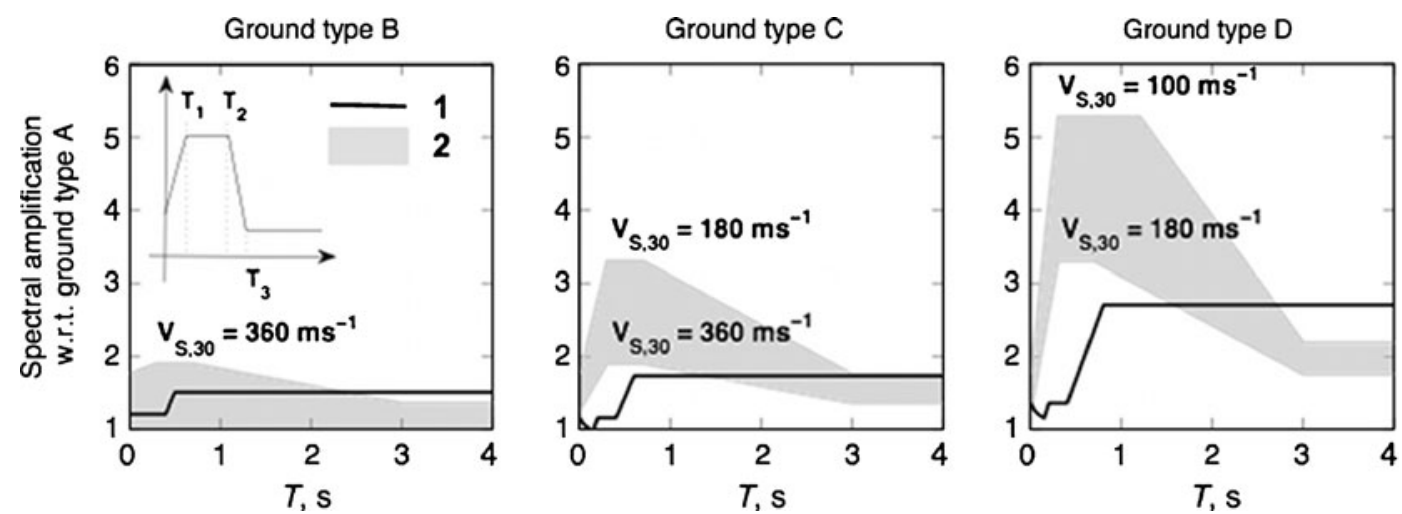

Fig. 13 Spectral envelopes (shaded bands 2) of site amplification, as given by Eq. 1 for ground type $B, C$, and $D .1$ is the spectral amplification due to site effects as prescribed by the Eurocode 8 (CEN 2004)

bound to $V_{S, 30}=360 \mathrm{~ms}^{-1}$, threshold between B and $\mathrm{C}$. Thus, the only change with respect to the Table 1 values is that $T_{3}=3 \mathrm{~s}$ is replaced by $2 T_{0,1 \mathrm{D}}=1.4 \mathrm{~s}$. Considering the different shapes of the Tarcento basin cross-section and of the Sismovalp valley (Fig. 14), the stiffer mechanical properties of the alluvium materials in the former, and also that response spectral amplification curves are not directly comparable to Fourier spectra ratios, we find it qualitatively remarkable that the simplified response spectral basin amplification factor for $V_{S, 30}=360 \mathrm{~ms}^{-1}$ lies close to the median SSR amplitudes at TSB (Fig. 11b), and slightly above them at TSC (Fig. 10b). Although we are using only weak motions records for the comparison, the noted agreement lends support to the simplified criteria just illustrated; these seem to adequately capture at least the frequency ranges where basin amplification effects are likely

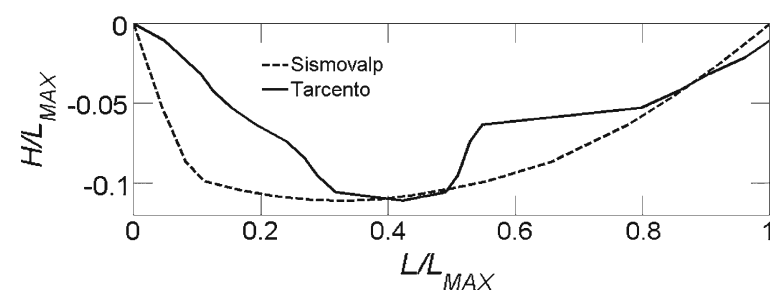

Fig. 14 Shape of the alluvium-filled Sismovalp project valley (see Lacave and Lemeille 2006, and also http://www. risknat.org/projets/sismovalp/CD2/Partners.html) and of Tarcento basin (NNE-SSW cross-section); horizontal distance $(L)$ and depth $(H)$ are normalized w.r. to the width $\left(L_{\text {MAX }}\right)$ to occur. Further testing of the simplified criteria in question against $\mathrm{SM}$ recordings from the L'Aquila 2009 ( $M_{W}$ 6.3), Italy, earthquake is illustrated elsewhere (Faccioli et al. 2010). These comparisons attest that the simulations capture well the frequency ranges of basin amplification effects. In the cited study it is also shown that the application of the previous simplified approaches within a seismic hazard assessment framework is apt to quantify basin amplification effects much better than just the uniform hazard UH spectra defined for soil, accounting for unspecific site effects.

Comparisons between analytical results and observations can be improved if the 2D Fourier spectral amplification curves for the Sismovalp model valley computed by Faccioli et al. (2010) are directly used, instead of the simplified criteria. In this case, the numerical transfer functions in each simulation at the valley surface receivers, segregated into "center" and "edge" zones, were first separately averaged and then their ratio was computed with respect to the Fourier spectrum of a reference receiver located on outcropping rock, near one edge of the valley. The median values of the spectral ratios of the different simulations were finally obtained, and are labeled as 2 in Figs. $10 \mathrm{~b}$ and $11 \mathrm{~b}$. The curves appear to capture quite well the key features of site amplification at both TSC and TSB for normalized frequencies $<2$. At higher frequencies, the apparent overestimation of spectral amplification values may in part be related to the frequency-dependent 
$Q$ model implemented in the computer program used for the simulations (see Stupazzini et al. 2009 and http://geoelse.stru.polimi.it/). However, the observed deviation could be also explained by the fact that the reference site TSH shows high amplification levels at frequencies $f>4 \mathrm{~Hz}$.

\section{Conclusions}

More than 30 years after the destructive seismic sequence of Friuli, NE Italy, of 1976-1977, we have first illustrated by means of weak motion recordings on the Tarcento basin, in the same region, a possible verification of the ground motion predictions contained in a pioneering microzonation study conducted therein in 1978-1979. The observations of weak earthquakes seem to confirm the validity of the main indications of the old study regarding the influence of soil local profiles and mechanical properties on site response.

In particular, in the zone of TSB station, where the alluvium sediments are deepest, the old study had indicated response spectrum amplification factors as high as 3.5 at periods around $1 \mathrm{~s}$, i.e., with reference to the normalized frequency representation of Fig. 11b, $f / f_{0,1 \mathrm{D}}=1.4$. At such frequency, the recent instrumental observations depicted by the shaded band in Fig. 11b confirm that amplification tends to be highest. In the same zone, high-frequency amplification tends to decrease to 1, quite in agreement with Fig. 11b. The comparison is also quite favorable at locations with smaller depth of sediments, such as at station TSC: in this case, as shown in Fig. 10b, the amplification at high frequency is somewhat higher than 1 (a level about 1.4 was reported in the old study).

After checking that standard 1D amplification analysis cannot explain the features of observed HVSRs and SSRs, we have subsequently explored whether the latter could be interpreted through simplified criteria and results obtained in previous parametric studies. These had used an idealized model of an Alpine valley, and a DRM approach to combine a finite source model in a $1 \mathrm{D}$ crustal velocity structure with a $2 \mathrm{D}$ spectral element model of the valley, whose sediments have $V_{S}$ increasing with depth.

The exploration has indicated that existing approximate criteria for estimating response spectral amplification on an alluvium-filled valley (Vanini et al. 2007) can qualitatively predict the average level of observed Fourier spectra amplification in terms of HVSRs and SSRs at Tarcento and, rather well, the significant frequency intervals. Application of such criteria is quite simple and only requires that one obtains an estimate of the fundamental 1D vibration frequency where the valley sediments are deepest, and that the Eurocode 8 subsoil category be known. We also showed that the results of previously cited, parametric simulation studies are apt to yield more refined estimates of the complex amplification effects observed at Tarcento. In view of the significant differences in valley shape and mechanical properties of the simulation models, this is a rather encouraging result, to be further strengthened by the analysis of other case histories.

Acknowledgements The Italian Ministry of Education, University and Research (MIUR) is acknowledged for partially funding the work reported herein, within the framework of the PRIN2007 (Research Project of National Interest) Project "Prediction of ground motion and generation of shaking maps in the near-fault region of an earthquake". Manuela Vanini has provided valuable cooperation in carrying out the $2 \mathrm{D}$ seismic response analyses, while Mario Ordaz has critically revised the manuscript and significantly contributed to its improvement. The Comune di Tarcento and the Forania di Tarcento are gratefully acknowledged for allowing us to install accelerographs at the TSH (Palazzetto dello Sport), TSC (Istituto Scolastico Comprensivo), and TSB (Chiesa di San Biagio) locations. Even though not individually acknowledged, a special mention is devoted to all those persons who have been involved in the surveillance of our instruments since October 2008. We would like to thank Nikos Theodoulidis and an anonymous reviewer for critically revising the manuscript and providing constructive comments and suggestions.

\section{References}

Aoudia A, Saraò A, Bukchin B, Suhadolc P (2000) The 1976 Friuli (NE Italy) thrust faulting earthquake: a reappraisal 23 years later. Geophys Res Lett 27:573576

Basili R, Valensise G, Vannoli P, Burrato P, Fracassi U, Mariano S, Tiberti MM, Boschi E (2008) The 
database of individual seismogenic sources (DISS), version 3: summarizing 20 years of research on Italy's earthquake geology. Tectonophysics. doi:10.1016/j. tecto.2007.04.014

Bard P-Y (2008) The H/V technique: capabilities and limitations based on the results of the SESAME project. Bulletin of Earthquake Engineering 6(1):1-2

Bielak J, Loukakis K, Hisada Y, Yoshimura C (2003) Domain reduction method for threedimensional earthquake modeling in localized regions. Part I: theory. Bull Seismol Soc Am 93:817-824

Bindi D, Parolai S, Spallarossa D, Cattaneo M (2000) Site effects by $\mathrm{H} / \mathrm{V}$ ratio: comparison of two different procedures. J Earthqu Eng 4(1):97-113

Borcherdt RD (1970) Effects of local geology on ground motion near San Francisco Bay. Bull Seismol Soc Am 60:29-61

Brambati A, Faccioli E (1980) Studio di microzonizzazione sismica dell'area di Tarcento (Friuli). Edito da Regione Autonoma Friuli Venezia Giulia e Università degli Studi di Trieste, con la collaborazione del Politecnico di Milano. (In Italian, with English abstract)

Burrato P, Poli ME, Vannoli P, Zanferrari A, Basili R, Galadini F (2008) Sources of Mw 5+ earthquakes in northeastern Italy and western Slovenia: an updated view based on geological and seismological evidence. Tectonophysics 453:157-176

Cauzzi C, Faccioli E (2008) Broadband (0.05 s to 20 s) prediction equations for displacement response spectra calibrated on a worldwide digital database. J Seismol 12:453-475

CEN - Comité Européen de Normalisation (2004) Eurocode 8: Design of structures for earthquake resistance - part 1: general rules, seismic actions and rules for buildings, Brussels

Chávez-García F, Faccioli E (2000) Complex site effects and building codes: making the leap. J Seismol 4(1): 23-40

Costa G, Moratto L, Suhadolc P (2009) The Friuli Venezia Giulia Accelerometric Network-RAF. Bulletin of Earthquake Engineering. doi:10.1007/ s10518-009-9157-y

Chatelain J-L, Guillier B, Cara F et al (2008) Evaluation of the influence of experimental conditions on $\mathrm{H} / \mathrm{V}$ results from ambient noise recordings. Bulletin of Earthquake Engineering 6(1):33-74

Cipar J (1981) Broadband time domain modelling of earthquakes from Friuli, Italy. Bull Seismol Soc Am 71:1215-1231

DISS Working Group (2009) Database of Individual Seismogenic Sources (DISS), Version 3.1.0: A compilation of potential sources for earthquakes larger than M 5.5 in Italy and surrounding areas. http://diss. rm.ingv.it/diss/, (c) INGV 2009 - Istituto Nazionale di Geofisica e Vulcanologia - All rights reserved

Faccioli E, Maggio F, Paolucci R, Quarteroni A (1997) 2D and 3D elastic wave propagation by a pseudospectral domain decomposition method. J Seismol 1:237-251
Faccioli E, Vanini M, Paolucci R, Stupazzini M (2005) Comment on "Domain reduction method for threedimensional earthquake modelling in localized regions, Part I: Theory" by J. Bielak, K. Loukakis, Y. Hisada, C. Yoshimura, and "Part II: verification and applications", by C. Yoshimura, J. Bielak, Y. Hisada, A. Fernández. Bull Seismol Soc Am 95:763-769

Faccioli E, Cauzzi C, Paolucci R, Vanini M, Villani M, Finazzi D (2007) Long period strong ground motion and its use as input to displacement based design. In: Pitilakis K (ed) Earthquake geotechnical engineering, 4th international conference on earthquake geotechnical engineering-invited lectures. Sect. 2: Springer, Netherlands, pp 23-51

Faccioli E, Villani M, Vanini M, Cauzzi C (2010) Mapping seismic hazard for the needs of displacement based design: the case of Italy. In: Fardis M (ed) Advances in performance-based earthquake engineering, chapter 1. Springer

Galadini F, Poli ME, Zanferrari A (2005) Seismogenic sources potentially responsible for earthquakes with $M \geq 6$ in the eastern Southern Alps (Thiene-Udine sector, NE Italy). Geophys J Int 161:739-762

Guillier B, Atakan K, Chatelain J-L, et al. (2008) Influence of instruments on the $\mathrm{H} / \mathrm{V}$ spectral ratios of ambient vibrations. Bulletin of Earthquake Engineering $6(1): 3-31$

Haghshenas E, Bard P-Y, Theodoulidis N et al. (2008) Empirical evaluation of microtremor $\mathrm{H} / \mathrm{V}$ spectral ratio. Bulletin of Earthquake Engineering 6(1):75108

Kanai K, Tanaka T (1961) On microtremors VIII. Bull Earthq Res Inst 39:97-114

Hisada Y, Bielak J (2003) A theoretical method for computing near-fault ground motions in layered halfspaces considering static offset due to surface faulting, with a physical interpretation of fling step and rupture directivity. Bull Seismol Soc Am 93(3):11541168

Konno K, Ohmachi T (1998) Ground-motion characteristics estimated from spectral ratio between horizontal and vertical components of microtremor. Bull Seismol Soc Am 88:228-241

Lacave C, Lemeille F (2006) Seismic hazard and alpine valley response analysis: generic valley configurations. In: Proc. 1st Europ. Conf. on Earthq. Engng. and Seismol., CD Rom, Paper No. 1, Geneva, Switzerland

Lachet C, Bard P-Y (1994) Numerical and theoretical investigations on the possibilities and limitations of Nakamura's technique. J Phys Earth 42:377-397

Lermo J, Chàvez-Garcìa F (1993) Site effects evaluation using spectral ratios with only one station. Bull Seismol Soc Am 83(5):1574-1594

Nakamura Y (1989) A method for dynamic characteristic estimation of subsurface using microtremor on the ground surface. Q Rep RTRI 30(1):25-33

Nakamura Y (2000) Clear identification of fundamental idea of Nakamura's technique and its application. In: Proceedings of the 12th world conference of earthquake engineering. Auckland, New Zealand 
Nogoshi M, Igarashi T (1971) On the amplitude characteristics of microtremor (part 2). Journal of the Seismological Society of Japan 24:26-40. (In Japanese with English abstract)

Pacor F, Bindi D, Luzi L, Parolai S, Marzorati S, Monachesi G (2007) Characteristics of strong ground motion data recorded in the Gubbio sedimentary basin (Central Italy). Bulletin of Earthquake Engineering 5:27-43

Paolucci R, Pacor F, Puglia R, Ameri G, Cauzzi C, Massa M (2010) Record processing in ITACA, the new Italian strong-motion database. In: Akkar S, Gulkan $\mathrm{P}$, van Eck T (eds) Earthquake data in engineering seismology-networks, data management and predictive models, chapter 8 . Springer

Parolai S, Richwalski SM, Milkereit C, Bormann P (2004) Assessment of the stability of $\mathrm{H} / \mathrm{V}$ spectral ratios from ambient noise and comparison with earthquake data in the Cologne area (Germany). Tectonophysics 390:57-73

Perniola B, Bressan G, Pondrelli S (2004) Changes in failure stress and stress transfer during the 1976-77 Friuli sequence. Geophys J Int 156:297-306
Pondrelli S, Ekstrom G, Morelli A (2001) Seismotectonic re-evaluation of the 1976 Friuli, Italy, seismic sequence. J Seismol 5:73-83

Slejko D, Neri G, Orozova I, Renner G, Wyss M (1999) Stress field in Friuli (NE Italy) from fault plane solutions of activity following the 1976 main shock. Bull Seismol Soc Am 89:1037-1052

Stupazzini M, Paolucci R, Igel H (2009) Near-fault earthquake ground motion simulation in the Grenoble Valley by a high-performance spectral element code. Bull Seismol Soc Am 99(1):286-301

Vanini M, Pessina V, Di Giulio G, Lenti L (2007) Influence of alluvium filled basins and edge effect on displacement response spectra. Deliverable D19 of Project S5, available at http://progettos5.stru. polimi.it/

Zonno G, Kind R (1984) Depth determination of north italian earthquakes using Grafenberg data. Bull Seismol Soc Am 74:1645-1659

Zollo A, Bobbio A, Emolo E, Herrero A, De Natale G (1997) Modelling of ground acceleration in the near source range: the case of 1976, Friuli earthquake $(\mathrm{M}=6.5)$, northern Italy. J Seismol 1:305-319 